\title{
Multi-objective optimization of oil well drilling using elitist non-dominated sorting genetic algorithm
}

\author{
Chandan Guria*, Kiran K Goli and Akhilendra K Pathak
}

Department of Petroleum Engineering, Indian School of Mines, Dhanbad 826004, India

(C) China University of Petroleum (Beijing) and Springer-Verlag Berlin Heidelberg 2014

\begin{abstract}
A multi-objective optimization of oil well drilling has been carried out using a binary coded elitist non-dominated sorting genetic algorithm. A Louisiana offshore field with abnormal formation pressure is considered for optimization. Several multi-objective optimization problems involving twoand three-objective functions were formulated and solved to fix optimal drilling variables. The important objectives are: (i) maximizing drilling depth, (ii) minimizing drilling time and (iii) minimizing drilling cost with fractional drill bit tooth wear as a constraint. Important time dependent decision variables are: (i) equivalent circulation mud density, (ii) drill bit rotation, (iii) weight on bit and (iv) Reynolds number function of circulating mud through drill bit nozzles. A set of non-dominated optimal Pareto frontier is obtained for the two-objective optimization problem whereas a non-dominated optimal Pareto surface is obtained for the three-objective optimization problem. Depending on the trade-offs involved, decision makers may select any point from the optimal Pareto frontier or optimal Pareto surface and hence corresponding values of the decision variables that may be selected for optimal drilling operation. For minimizing drilling time and drilling cost, the optimum values of the decision variables are needed to be kept at the higher values whereas the optimum values of decision variables are at the lower values for the maximization of drilling depth.
\end{abstract}

Kew words: Drilling performance, rate of penetration, abnormal pore pressure, genetic algorithm, multiobjective optimization

\section{Introduction}

The technical cost of crude oil depends largely on the expenditures due to exploration, development and production operations. Among them, exploration expenditure is primarily due to geological and geophysical surveys along with drilling activities. Development expenditure normally includes the cost of amortization of several wells that must be drilled to produce hydrocarbon economically. The relative magnitude of exploration and development expenditure varies from field to field and depends on the difficulties present in the field. In general, exploration and development contribute approximately $50 \%-80 \%$ of total expenditure. In this regard, drilling also plays an important role and contributes $65 \%$ $80 \%$ of exploration and development cost. Expenditures are also increasingly added to recover additional amounts of oil and gas for given hydrocarbon in place. Details of exploration and development expenditures for different oil wells have been discussed by Masseron (1990). The cost of drilling is usually expressed as the cost per footage or meterage drilled, and depends on type of rig used, geographic location and target drilling depth. Cost of drilling is also influenced by

*Correspondence author. email: cguria.che@gmail.com

Received May 6, 2013 drill bit rotating time, trip time, connection time, cost of drill bits and rig cost. The drill bit rotating time depends on several drilling variables e.g., wellbore stability, class of drill bit, weight on bit, rotary speed of drill bit, drilling mud properties, hydraulics of drilling mud, drill bit tooth wear and drill bit bearing wear. Depending upon the drilling difficulties, the cost of drilling increases with depth in a parabolic manner up to about 3,000 meters, and then exponentially increases beyond 4,000 meters (Masseron, 1990). Therefore, marginal improvement in drilling cost may reduce exploration and development costs to a significant extent.

To predict the rate of penetration (ROP) and the best set of operating drilling variables, different drilling models are proposed in terms of rock properties and drilling variables which are discussed in standard texts (Adams, 1985; Mitchell, 1992; Bourgoyne et al, 2003). Graham and Muench (1959) determined the optimum values of weight on bit (WOB) and rotary speed (revolution per minute, rpm) of the drill bit to minimize the drilling costs based on field data. The most common and popular ROP model used in drilling industry is the $d_{\mathrm{c}}$-exponent method (Bingham, 1964) which was based on rock mechanics principles. Jordan and Shirley (1966) modified Bingham's equation and proposed drillability function which depends on depth and strength of formation. Rehm and McClendon (1971) further modified Jordan and 
Shirley's ROP equation by incorporating the actual weight of drilling mud. This ROP model has an ability to detect and quantify abnormal pore pressure accurately. Bourgoyne and Young (1974) developed a comprehensive nonlinear drilling model to predict drilling performance, abnormal formation pressure and optimal operating drilling variables. They performed multiple regression analysis to determine the constants present in the drilling model using field data and developed a relatively simple analytical procedure to determine the best values of the operating drilling variables to minimize the cost of drilling. Reza and Alcocer (1986) developed a dynamic nonlinear, multi-dimensional and dimensionless drilling model for deep drilling applications using the Buckingham $\pi$-theorem (Buckingham, 1914). They proposed three equations for the drilling model, namely, rate of penetration, rate of bit dulling and rate of bearing wear involving several drilling variables for example WOB, rotary speed of the drill bit, bit diameter, bit nozzle diameter, bit bearing diameter, drilling fluid characteristics (particularly, density and viscosity), drilling fluid circulation rate, differential pressure between formation and bottom hole, rock hardness, bottom hole temperature and heat transfer coefficient. Maidla and Ohara (1991) developed an optimization technique based on Bourgoyne and Young (1974) using field data particularly WOB and the rotary speed of the drill string for a given roller-cutter bit to minimize the drilling cost for a single bit run. Iqbal (2008) presented a stepwise drilling optimization procedure using real time data for roller-cutter bit insertion. In this methodology, the WOB exponent was evaluated first for a given ROP, and then the optimum rotary speed of the drill string and WOB parameters were determined using correlations. Recently, Bahari and Baradaran $(2007 ; 2009)$ have proposed to minimize drilling cost for the Iranian Khangiran gas field based on the ROP model of Bourgoyne and Young (1974).

So far, drilling optimization studies are mostly based on minimizing the cost of drilling operation. However, the optimal drilling process operation is associated with several important conflicting and non-commensurate objectives that need to be optimized simultaneously in the presence of suitable constraints. In addition to minimize the cost of drilling, one may achieve the highest possible rate of penetration by minimizing the drilling time and maximizing the drilling depth simultaneously for a given degree of fractional wear of the drill bit tooth. The above objectives are mutually conflicting in nature, i.e., in order to maximize the rate of penetration by maximizing the drilling depth and minimizing the drilling time, it is difficult to minimize the cost of drilling at the same time for given fractional drill bit tooth wear. Therefore, oil well drilling operation is an ideal candidate for multi-objective optimization.

Multi-objective optimization has been a highly demanding research topic in last decade as most of the real-world decision making problems involve trade-offs between conflicting objectives. Over the years, the AI-based genetic algorithm (GA) has been used as a powerful tool for the optimization studies for scientists and engineers. Several researchers have extended the basic algorithm GA (Goldberg, 2001) to solve multi-objective optimization problems and the topic was reviewed by Deb (2001) and Coello Coello (2002). A popular algorithm used for multi-objective optimization problems is the elitist non-dominated sorting genetic algorithm (NSGAII) developed by Deb and his research group (Deb, 2001; Deb et al, 2002). Nowadays, NSGA-II has been applied to solve highly computer intensive problems in the field of petroleum engineering related problems (gas lift optimization: Ray and Sarker, 2007; Rashid, 2010; water flooding performance: Han et al, 2011; oil production planning: Singh et al, 2013).

In this study, a model based on multi-objective drilling optimization has been implemented using the elitist nondominated sorting genetic algorithm. The drilling model of Bourgoyne and Young (1974) has been used to predict the ROP and fractional tooth wear. Pore pressure variation with true vertical depth (TVD) has been predicted using the field data of the Louisiana offshore formation to calculate the variation of drilling depth and fractional wear loss of the drill bit with drilling time, and has been used for optimization studies. Several multi-objective optimization problems are formulated involving conflicting objectives, namely, maximization of the final drilling depth, minimization of the final drilling time and minimization of the drilling cost. The drill bit tooth wear is the only constraint involved in the present optimization studies. The important decision variables associated with the drilling optimization problems are the trajectories (or histories) of (i) rotary speed of the drill bit, (ii) WOB, (iii) equivalent circulation density (ECD) and (iv) Reynolds number function based on the circulating drilling mud through the drill bit nozzle while drilling. It is also mentioned that this is the first study in the field of multi-objective optimization of oil well drilling involving conflicting objectives.

\section{Formulation}

\subsection{Mathematical model for drilling operation}

\subsubsection{Rate of penetration}

The drilling model proposed by Bourgoyne and Young (1974) is used to predict ROP while drilling. This model is simple and accurate involving most of the drilling parameters, such as nature of formation, type of drill bit and operating drilling variables (e.g., rotary speed of the drill bit, WOB, ECD, Reynolds number function based on the circulating drilling fluids through drill bit nozzles while drilling, and fraction of drill bit tooth wear). According to this model, the rate of penetration $(\mathrm{ft} / \mathrm{h})$ is given by the following nonlinear equation:

$$
\begin{aligned}
\frac{\mathrm{d} D}{\mathrm{~d} t}= & \exp \left[a_{1}+a_{2}(1000-D)+a_{3}\left(p p g_{\mathrm{p}}-9.0\right) D^{0.69}+\right. \\
& a_{4} D\left(p p g_{\mathrm{p}}-\rho_{\mathrm{c}}\right)+a_{5} \ln \frac{\left(\frac{w}{d}\right)-\left(\frac{w}{d}\right)_{\mathrm{t}}}{4.0-\left(\frac{w}{d}\right)_{\mathrm{t}}}+ \\
& \left.a_{6} \ln \frac{N}{100}-a_{7} h+a_{8} \operatorname{Re}_{\mathrm{f}}\right]
\end{aligned}
$$

Details of the estimating model constants (i.e., $a_{1}$ to $a_{8}$ ) are 
as described by Bourgoyne and Young (1974) and determined using non-linear multiple regression analysis.

\subsubsection{Drill bit tooth wear}

In addition to the ROP model, prediction of the drill bit wear while drilling is also important. Usually, a drill bit replacement takes place if the fractional tooth wear of the drill bit is more than $75 \%$ of tooth height. A composite tooth wear equation can be obtained by considering tooth geometry, WOB and rotary speed of the drill bit. Thus, the instantaneous rate of tooth wear is given by the following equation (Bourgoyne and Young, 1974):

$$
\frac{\mathrm{d} h}{\mathrm{~d} t}=\frac{H_{3}}{\tau_{\mathrm{H}}}\left(\frac{N}{100}\right)^{H_{1}} \frac{\left(\frac{w}{d}\right)_{\max }-4.0}{\left(\frac{w}{d}\right)_{\max }-\frac{w}{d}} \frac{1+\frac{H_{2}}{2}}{1+H_{2} h}
$$

In the above equation, $w / d$ is the weight on bit per inch of bit diameter, whereas $(w / d)_{\max }$ is the bit weight per inch of bit diameter at which the bit tooth will fail instantaneously. $\mathrm{H}_{1}, \mathrm{H}_{2}$ and $\mathrm{H}_{3}$ are the tooth wear parameters for a given type of bit. Now, Eq. (2) is simplified to obtain the formation abrasiveness constant at $h=1$ by the following equation:

$$
\tau_{\mathrm{H}}=\left(\frac{N}{100}\right)^{H_{1}} \frac{\left(\frac{w}{d}\right)_{\max }-4.0}{\left(\frac{w}{d}\right)_{\max }-\frac{w}{d}} \frac{1+\frac{H_{2}}{2}}{1+H_{2} h} t_{\mathrm{b}}
$$

The abrasiveness factor $\tau_{\mathrm{H}}$ is numerically equal to the hours of the tooth life if the bit operates at standard conditions i.e., a bit weight of $1000 \mathrm{lb}$ per inch of bit diameter with speed of $100 \mathrm{rpm}$.

\subsubsection{Drill bit bearing wear}

The instantaneous rate of bearing wear depends on the condition of the drill bit while drilling and the rate of bearing wear also increases when the bearing surfaces are damaged. The bit bearing life is assumed to vary linearly with the rotary speed of the drill bit and WOB, and the corresponding drill bit bearing wear is expressed in the following form (Bourgoyne and Young, 1974):

$$
\frac{\mathrm{d} B}{\mathrm{~d} t}=\frac{1}{\tau_{\mathrm{b}}} \frac{N}{100}\left(\frac{w}{4 d}\right)^{b}
$$

In the above equation, exponent $b$ depends upon the type of bearing and the quality of drilling fluid used. The bearing constant, $\tau_{\mathrm{b}}$, is calculated from dull bit grading. Usually the drill bit tooth wearing takes place at a much faster rate than the bearing wear. So the present study considers only drill bit wear (i.e., Eq. (2)) instead of drill bit bearing wear (i.e., Eq. (4)) for the optimal analysis of drilling operation. Therefore, Eqs. (1) and (2) are the desired differential equations to predict the performance of drilling operation and solved simultaneously with appropriate initial conditions. In subsequent sections, $w / d=W(t)$ is considered for simplification.

\subsection{Prediction of pore pressure}

To determine the drilling depth and drill bit wear (i.e., Eqs. (1) and (2)), it is necessary to know the variation of the pore pressure with TVD. The pore pressure depends on fracture pressure gradient, Poisons ratio, density, surface porosity and porosity decline constant of the formation. The variation of the pore pressure with TVD is given by the following relation (Bourgoyne et al, 2003):

$$
p p g_{\mathrm{p}}=\frac{\operatorname{ppg}_{\mathrm{g}} \frac{\mu}{2 \mu-1}\left[1-\frac{\phi_{0}}{K D}\left(1-\mathrm{e}^{-K D}\right)\right]-\frac{1-\mu}{2 \mu-1} p p g_{\mathrm{fr}}}{1-\frac{\mu}{2 \mu-1} \frac{\phi_{0}}{K D}\left(1-\mathrm{e}^{-K D}\right)}
$$

In Eq. (5), the fracture pressure gradient $\left(p p g_{\text {fr }}\right)$ usually increases with depth, whereas Poisson's ratio $(\mu)$ declines with the formation depth. Other parameters, namely, the surface formation porosity $\left(\phi_{0}\right)$, the porosity decline rate constant $(K)$ and the grain density $\left(p p g_{\mathrm{g}}\right)$ are almost independent of the formation depth and assumed to be invariant with depth in the present study.

\subsection{Parameter estimation for pore pressure}

To know the variation of pore pressure with TVD, it is essential to determine $K, p p g_{\mathrm{g}}, p p g_{\mathrm{fr}}, \mu$, and $\phi_{0}$ in Eq. (5). For this, the normalized weighted square of the errors $(E)$ between the actual pore pressure and the predicted pore pressure is minimized at different drilling depths. The possible decision variables for this error minimization problem are: $K, p p g_{\mathrm{g}}, p p g_{\mathrm{fr}}, \mu$, and $\phi_{0}$. Therefore, a single objective function optimization problem for pore pressure estimation is formulated and written as:

\section{Problem 1}

$$
\min \left[E\left(K, p p g_{\mathrm{g}}, p p g_{\mathrm{fr}}, \mu, \phi_{0}\right)\right]=w_{0}\left(1-\frac{p p g_{\mathrm{p}, \mathrm{cal}}}{p p g_{\mathrm{p}, \mathrm{d}}}\right)^{2}
$$

subject to (s.t.)

Bounds on the decision variables:

$$
\begin{aligned}
& K_{\mathrm{L}} \leq K \leq K^{\mathrm{U}} \\
& p p g_{\mathrm{g}, \mathrm{L}} \leq p p g_{\mathrm{g}} \leq p p g_{\mathrm{g}}{ }^{\mathrm{U}} \\
& p p g_{\mathrm{fr}, \mathrm{L}} \leq p p g_{\mathrm{fr}} \leq p p g_{\mathrm{fr}} \mathrm{U} \\
& \mu_{\mathrm{L}} \leq \mu \leq \mu^{\mathrm{U}} \\
& \phi_{0, \mathrm{~L}} \leq \phi_{0} \leq \phi_{0}^{\mathrm{U}}
\end{aligned}
$$

Subscript $d$ in the objective function (Eq. (6a)) describes the desired value of the pore pressure gradient. The right hand side of Eq. (6a) is multiplied by a large weighting factor, $w_{0}$, which depends on the relative magnitude of square of the errors in the objective function (Deb, 2001). 


\subsection{Drilling optimization}

For drilling optimization, several multi-objective optimization problems are formulated involving conflicting objectives. First a two-objective optimization problem is considered where minimizing the normalized final drilling time $\left(t_{f} / t_{\mathrm{ref}}\right)$ is the first objective function and the maximization of non-dimensional drilling depth $\left(D_{\mathrm{f}} / D_{\text {ref }}\right)$ is the second objective function. Here, $t_{\mathrm{f}}$ and $D_{\mathrm{f}}$ are the final drilling time and drilling depth respectively for the given single drill bit run, whereas $t_{\text {ref }}$ and $D_{\text {ref }}$ are the constant reference final drilling time and depth for the single bit run respectively. The major decision variables that influence ROP during drilling operation are: (i) ECD: $\rho_{\mathrm{c}}(t)$, (ii) rotary speed of the drill bit: $N(t)$, (iii) WOB: $W(t)$ and (iv) Reynolds number of function of the circulating fluid through drill bit nozzles: $\operatorname{Re}_{\mathrm{f}}(t) . N(t)$ and $W(t)$ have direct influence on the rate of penetration, whereas $\rho_{\mathrm{c}}(t)$ is manipulated to maintain the stability of the wellbore at the bottom hole by adjusting the static mud density at the surface. Similarly, $\mathrm{Re}_{\mathrm{f}}$ is also manipulated in such a way that it will help to adjust drilling fluid properties and drilling fluid hydraulics while drilling. Reynolds number function based on drill bit nozzle, $\operatorname{Re}_{\mathrm{f}}(t)$, is defined by $\frac{\rho_{\mathrm{c}} q}{350 \mu d_{\mathrm{n}}}$ where $\mu, \rho_{\mathrm{c}}$, $q$ and $d_{\mathrm{n}}$ are the apparent viscosity at $10,000 \mathrm{~s}^{-1}, \mathrm{ECD}$, mud circulation rate and the diameter of the drill bit nozzle are expressed in oil field units. Knowing $\operatorname{Re}_{\mathrm{f}}(t)$, one may able to calculate the jet velocity through the drill bit nozzle, and hence the jet impacting force or the hydraulic horse power. Here it is mentioned that the decision variables are not fixed (or unique) values and they are all varying with drilling depth or drilling time. Usually, drilling is carried out till the specified fractional tooth wear loss of the drill bit $\left(h_{\mathrm{d}}\right)$ is reached. To obtain the required drill bit fractional tooth wear $\left(h_{\mathrm{d}}\right)$, the first objective function, $f_{1}$, is written in the form of a penalty function with a large weighing factor, $w_{1}$, and is written as (Deb, 2001):

$$
f_{1}\left[N(t), W(t), \rho_{\mathrm{c}}(t), \operatorname{Re}_{\mathrm{f}}(t)\right]=\frac{t_{\mathrm{f}}}{t_{\mathrm{ref}}}+w_{1}\left(1-\frac{h}{h_{\mathrm{d}}}\right)^{2}
$$

The second objective function, $f_{2}$, involves the maximization of the final normalized drilling depth $\left(D_{\mathrm{f}} / D_{\text {ref }}\right)$ for a single bit run. Similarly to achieve the desired fractional tooth wear loss (i.e., $h_{\mathrm{d}}$ ), the objective function $\left(f_{2}\right)$ is written in the form of penalty function with a large weighing factor, $w_{2}$, and is given by the following equation (Deb, 2001):

$$
f_{2}\left[N(t), W(t), \rho_{\mathrm{c}}(t), \operatorname{Re}_{\mathrm{f}}(t)\right]=\frac{D_{\mathrm{f}}}{D_{\text {ref }}}-w_{2}\left(1-\frac{h}{h_{\mathrm{d}}}\right)^{2}
$$

Therefore, considering the above two mutually conflicting objective functions (i.e., Eqs. (7) and (8)), one may write the following two-objective optimization problem:

\section{Problem 2}

$$
\begin{aligned}
& \min \left\{f_{1}\left[N(t), W(t), \rho_{\mathrm{c}}(t), \operatorname{Re}_{\mathrm{f}}(t)\right]\right\}=\frac{t_{\mathrm{f}}}{t_{\text {ref }}}+w_{1}\left(1-\frac{h}{h_{\mathrm{d}}}\right)^{2} \\
& \max \left\{f_{2}\left[N(t), W(t), \rho_{\mathrm{c}}(t), \operatorname{Re}_{\mathrm{f}}(t)\right]\right\}=\frac{D_{\mathrm{f}}}{D_{\text {ref }}}-w_{2}\left(1-\frac{h}{h_{\mathrm{d}}}\right)^{2}
\end{aligned}
$$

subject to (s.t.)

Model equations (i.e., Eqs. (1) and (2)) with

Initial conditions, i.e., $D(t=0)=D_{0}$ and $h(t=0)=h_{0}$ Bounds on the decision variables:

$$
\begin{aligned}
& N(t)_{\mathrm{L}} \leq N(t) \leq N(t)^{\mathrm{U}} \\
& W(t)_{\mathrm{L}} \leq W(t) \leq W(t)^{\mathrm{U}} \\
& \rho_{\mathrm{c}}(t)_{\mathrm{L}} \leq \rho_{\mathrm{c}}(t) \leq \rho_{\mathrm{c}}(t)^{\mathrm{U}} \\
& \operatorname{Re}_{\mathrm{f}}(t)_{\mathrm{L}} \leq \operatorname{Re}_{\mathrm{f}}(t) \leq \operatorname{Re}_{\mathrm{f}}(t)^{\mathrm{U}}
\end{aligned}
$$

Constraint:

$$
h=h_{\mathrm{d}}
$$

Subscript $d$ describes the desired value of the fractional drill bit wear in the objective functions (Eqs. (9a) and (9b)) and constraint (Eq. (9e)).

In addition to above two objectives, cost of drilling is also an important objective which will determine whether the drilling operation can be carried out economically or not. According to Bourgoyne and Young (1974), the drilling cost is given by the following equation:

$$
C_{\mathrm{f}}=\frac{C_{\mathrm{b}}+C_{\mathrm{r}}\left(t_{\mathrm{b}}+t_{\mathrm{c}}+t_{\mathrm{t}}\right)}{\Delta D}
$$

Therefore, the third objective function may also be constructed in the form of normalized drilling cost (i.e. $C_{\mathrm{f}}$ / $C_{\text {ref }}$ ) where $C_{\text {ref }}$ is the constant reference cost. Similarly to achieve the desired values of the drill bit fractional wear $\left(h_{\mathrm{d}}\right)$, the third objective function, $f_{3}$, is also written in the form of a penalty function with a large weighting factor, $w_{3}$, and is written as (Deb, 2001):

$$
f_{3}\left[N(t), W(t), \rho_{\mathrm{c}}(t), \operatorname{Re}_{\mathrm{f}}(t)\right]=\frac{C_{\mathrm{f}}}{C_{\text {ref }}}+w_{3}\left(1-\frac{h}{h_{\mathrm{d}}}\right)^{2}
$$

Therefore, considering the above three conflicting objective functions (i.e., Eqs. (7), (8) and (11)), one may write the following three-objective optimization problem in the following way:

\section{Problem 3}

$$
\begin{aligned}
& \min \left\{f_{1}\left[N(t), W(t), \rho_{\mathrm{c}}(t), \operatorname{Re}_{\mathrm{f}}(t)\right]\right\}=\frac{t_{\mathrm{f}}}{t_{\text {ref }}}+w_{1}\left(1-\frac{h}{h_{\mathrm{d}}}\right)^{2} \\
& \max \left\{f_{2}\left[N(t), W(t), \rho_{\mathrm{c}}(t), \operatorname{Re}_{\mathrm{f}}(t)\right]\right\}=\frac{D_{\mathrm{f}}}{D_{\text {ref }}}-w_{2}\left(1-\frac{h}{h_{\mathrm{d}}}\right)^{2} \\
& \min \left\{f_{3}\left[N(t), W(t), \rho_{\mathrm{c}}(t), \operatorname{Re}_{\mathrm{f}}(t)\right]\right\}=\frac{C_{\mathrm{f}}}{C_{\text {ref }}}+w_{3}\left(1-\frac{h}{h_{\mathrm{d}}}\right)^{2}
\end{aligned}
$$

subject to (s.t.)

Model equations (i.e., Eqs. (1) and (2)) with Initial conditions, i.e., $D(t=0)=D_{0}$ and $h(t=0)=h_{0}$ 
Bounds on the decision variables:

$$
\begin{aligned}
& N(t)_{\mathrm{L}} \leq N(t) \leq N(t)^{\mathrm{U}} \\
& W(t)_{\mathrm{L}} \leq W(t) \leq W(t)^{\mathrm{U}} \\
& \rho_{\mathrm{c}}(t)_{\mathrm{L}} \leq \rho_{\mathrm{c}}(t) \leq \rho_{\mathrm{c}}(t)^{\mathrm{U}} \\
& \operatorname{Re}_{\mathrm{f}}(t)_{\mathrm{L}} \leq \operatorname{Re}_{\mathrm{f}}(t) \leq \operatorname{Re}_{\mathrm{f}}(t)^{\mathrm{U}}
\end{aligned}
$$

Constraint:

$$
h=h_{\mathrm{d}}
$$

Penalty functions are usually added to or subtracted from the objective functions for minimization of the objective function and maximization of the objective function respectively. The use of penalty functions involving ' $h$ ' in all the objective functions is to stop the integration of the state variable equations to ensure that one can obtain the optimal solutions within the desired values of ' $h$ '. A popular transformation for an objective function, $f$, that has to be minimized, to one involving the fitness function, $F$, that has to be maximized, is given by

$$
F=\frac{1}{1+f}
$$

This transformation does not alter the optimal solutions (Deb, 2001).

\section{Results and discussion}

\subsection{Pore pressure parameter estimation}

For the evaluation of drilling models and optimization studies, it is required to estimate the unknown parameters in the pore pressure equation (Eq. (5)). Eq. (6) is solved using a single-objective binary coded simple GA. To predict pore pressure with TVD, the offshore Louisiana well has been considered in the present study. The Louisiana formation (Bourgoyne and Young, 1974) shows characteristic abnormal formation pressure. At about 11,940.0 ft depth the formation pressure increases abnormally. The details of the drill data along with pore pressure data are given by Bourgoyne and Young (1974). Here, the possible decision variables that influence pore pressure are: porosity decline constant $(K)$, grain density $\left(p p g_{\mathrm{g}}\right)$, fracture pressure gradient $\left(p p g_{\mathrm{fr}}\right)$, Poisson's ratio $(\mu)$ and surface porosity $\left(\phi_{0}\right)$. Upper and lower limits of these decision variables are chosen according to Bourgoyne et al. (2003) and are given by: $8.0 \times 10^{-5} \mathrm{ft}^{-1} \leq K$ $\leq 9.0 \times 10^{-5} \mathrm{ft}^{-1}, 20.0 \mathrm{lb} / \mathrm{gal} \leq p p g_{\mathrm{g}} \leq 30.0 \mathrm{lb} / \mathrm{gal}, 8.33 \mathrm{lb} / \mathrm{gal}$ $\leq p p g_{\text {fr }} \leq 25.0 \mathrm{lb} / \mathrm{gal}, 0.18 \leq \mu \leq 0.28$ and $0.35 \leq \phi_{0} \leq 0.42$. The value of the weighting factor, $w_{0}$, is fixed at $10^{7}$ for this problem. The best values of computational parameters used for solving this optimization problem are: the maximum number of generations $=100000$, the size of population $=$ 100 , the length of substring $=32$, the length of chromosome $=32 \times 5=160$, the crossover probability $=0.95$, the mutation probability $=0.01$ and the random seed number $=0.6859$. The central processing unit (CPU) time required for this problem is $\sim 5.0$ minutes on an Intel computer (CPU T2050@ 1.60
GHz, 504 MB RAM). The computational parameters to be used in the code are tuned until the best results are obtained. Eq. (6) is solved separately using simple GA for thirty different values of pore pressure (Bourgoyne and Young, 1974). Usually the values of $K, p p g_{\mathrm{g}}$ and $\phi_{0}$ are independent of the formation depth and almost constant values are obtained for first five consecutive drilling depths from top. Hence, the average optimal values of $K, p p g_{\mathrm{g}}$ and $\phi_{0}$ have been considered for other drilling depths for parameter estimation. The average optimum values for these decision variables are found to be: $K=8.4 \times 10^{-5} \mathrm{ft}^{-1}, p p g_{\mathrm{g}}=24.88 \mathrm{lb} / \mathrm{gal}$ and $\phi_{0}=0.38$. Optimum values of other two decision variables i.e., fracture pressure gradient $\left(p p g_{\mathrm{fr}}\right)$ and Poisson's ratio $(\mu)$ are given in Table 1 for all the drilling depths. Variation of normalized fracture pressure $\left(p p g_{\mathrm{fr}, \mathrm{n}}=p p g_{\mathrm{fr}} / p p g_{\mathrm{fr}, \mathrm{ref}}\right)$ and Poisson's ratio with normalized depth $\left(D_{\mathrm{n}}=D / D_{\text {ref }}\right)$ are also shown in Figs. 1(a) and 1(b) respectively. A value of $18.2 \mathrm{lb} /$ gal is taken as a maximum fracture pressure (Table 1) and used as reference $p p g_{\mathrm{fr}}$. Similarly, the normalized TVD $\left(D_{\mathrm{n}}\right)$ is considered as $D / 20265$ where the maximum drilling depth (i.e., 20,265 ft) is considered as the reference drilling depth $\left(D_{\text {ref }}\right)$. It is noticed that fracture pressure gradient varies in the same way as the pore pressure varies with TVD. The sharp or abnormal variation of $p p g_{\mathrm{fr}, \mathrm{n}}$ with $D_{\mathrm{n}}$ has been taken care of by introducing the error function in the proposed equation. The adjustable parameters were determined in accordance with the methodology adopted by Tiwary and Guria (2010). The variation of fracture pressure gradient with the depth is given

\begin{tabular}{|c|c|c|c|c|c|}
\hline \multirow{2}{*}{$\begin{array}{c}\text { Depth } \\
\mathrm{ft}\end{array}$} & \multicolumn{2}{|c|}{ Optimum values } & \multirow{2}{*}{$\begin{array}{c}\text { Depth } \\
\mathrm{ft}\end{array}$} & \multicolumn{2}{|c|}{ Optimum values } \\
\hline & $\mu$ & $p p g_{\mathrm{fr}}, \mathrm{lb} / \mathrm{gal}$ & & $\mu$ & $p p g_{\text {fr }}, \mathrm{lb} / \mathrm{gal}$ \\
\hline 9515 & 0.25 & 12.9 & 12900 & 0.23 & 18.0 \\
\hline 9830 & 0.25 & 13.0 & 12975 & 0.22 & 18.0 \\
\hline 10130 & 0.24 & 12.8 & 13055 & 0.21 & 18.0 \\
\hline 10250 & 0.25 & 12.9 & 13250 & 0.21 & 18.0 \\
\hline 10390 & 0.24 & 12.8 & 13795 & 0.21 & 18.0 \\
\hline 10500 & 0.23 & 12.7 & 14010 & 0.21 & 18.0 \\
\hline 10575 & 0.23 & 12.8 & 14455 & 0.21 & 18.0 \\
\hline 10840 & 0.23 & 12.8 & 14695 & 0.21 & 18.0 \\
\hline 10960 & 0.23 & 12.9 & 14905 & 0.21 & 18.2 \\
\hline 11060 & 0.23 & 12.9 & 15350 & 0.20 & 18.2 \\
\hline 11475 & 0.23 & 12.9 & 15740 & 0.20 & 18.2 \\
\hline 11775 & 0.24 & 13.6 & 16155 & 0.20 & 18.2 \\
\hline 11940 & 0.24 & 15.4 & 16325 & 0.20 & 18.2 \\
\hline 12070 & 0.22 & 15.6 & 17060 & 0.20 & 18.2 \\
\hline 12315 & 0.23 & 16.8 & 20265 & 0.19 & 18.2 \\
\hline
\end{tabular}
by the following equation:

$$
p p g_{\mathrm{fr}, \mathrm{n}}=1-\frac{\operatorname{erf}\left[\left\{10^{5}\left(1-D_{\mathrm{n}}\right)^{14}\right\} / D_{\mathrm{n}}\right]}{3.38}
$$

Table 1 Optimal variation of Poisson's ratio and fracture pressure gradient (for $K=8.4 \times 10^{-5} \mathrm{ft}^{-1}, p p g_{\mathrm{g}}=24.9 \mathrm{lb} / \mathrm{gal}$ and $\phi_{0}=0.38$ ) 
The calculated normalized $p p g_{\text {fr }}$ (i.e., $p p g_{\text {fr, }}$ in Eq. (14)) and the actual normalized $p p g_{\text {fr }}$ (Bourgoyne and Young, 1974) have been compared at different normalized drilling depths and results are found to be satisfactory (Fig. 1(a)). Similarly, the variation of Poisson's ratio with $D_{\mathrm{n}}$ (Fig. 1(b)) is given by the following equation with a correlation coefficient more than 0.9:

$$
\mu=0.180 D_{\mathrm{n}}^{2}-0.37 D_{\mathrm{n}}+0.39
$$

To check the accuracy of pore pressure prediction, Eqs. (14) and (15) along with other optimum pore pressure parameters (i.e., $K, p p g_{\mathrm{g}}$ and $\phi_{0}$ ), ROP at a different

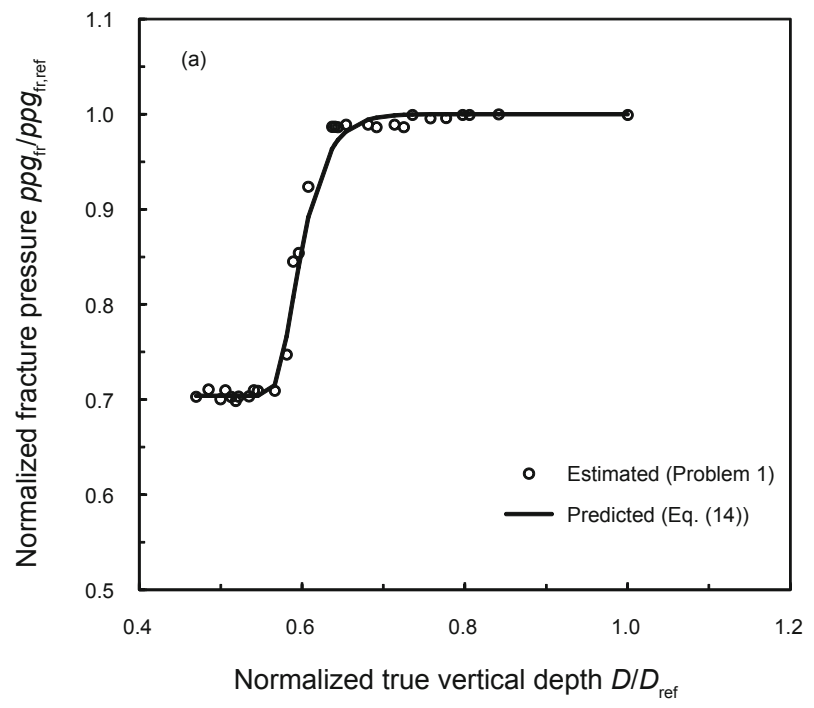

drilling depth has been calculated using Eq. (1) with model parameters for well No. 1 with a depth range of from 9,500 to $20,000 \mathrm{ft}$ of the Gulf coast area of Louisiana (i.e., $a_{1}=3.78$, $a_{2}=0.17 \times 10^{-3}, a_{3}=0.20 \times 10^{-3}, a_{4}=0.43 \times 10^{-4}, a_{5}=0.43, a_{6}$ $=0.21, a_{7}=0.41$ and $a_{8}=0.16$ ). Details of the comparison between calculated and predicted ROP for the offshore Louisiana formation is shown in Fig. 2(a), whereas the percent error prediction for ROP with drilling depth is shown in Fig. 2(b). It is observed that most of the ROP predictions almost matched with the actual values (except at 10,500 and $14,000 \mathrm{ft}$ depths with errors of $17 \%$ and $15 \%$ respectively) and the calculated average absolute deviation for all depths is found to be only $0.23 \%$.

Fig. 1 Variation of (a) normalized fracture pressure with normalized true vertical depth, and (b) Poisson's ratio with normalized true vertical depth
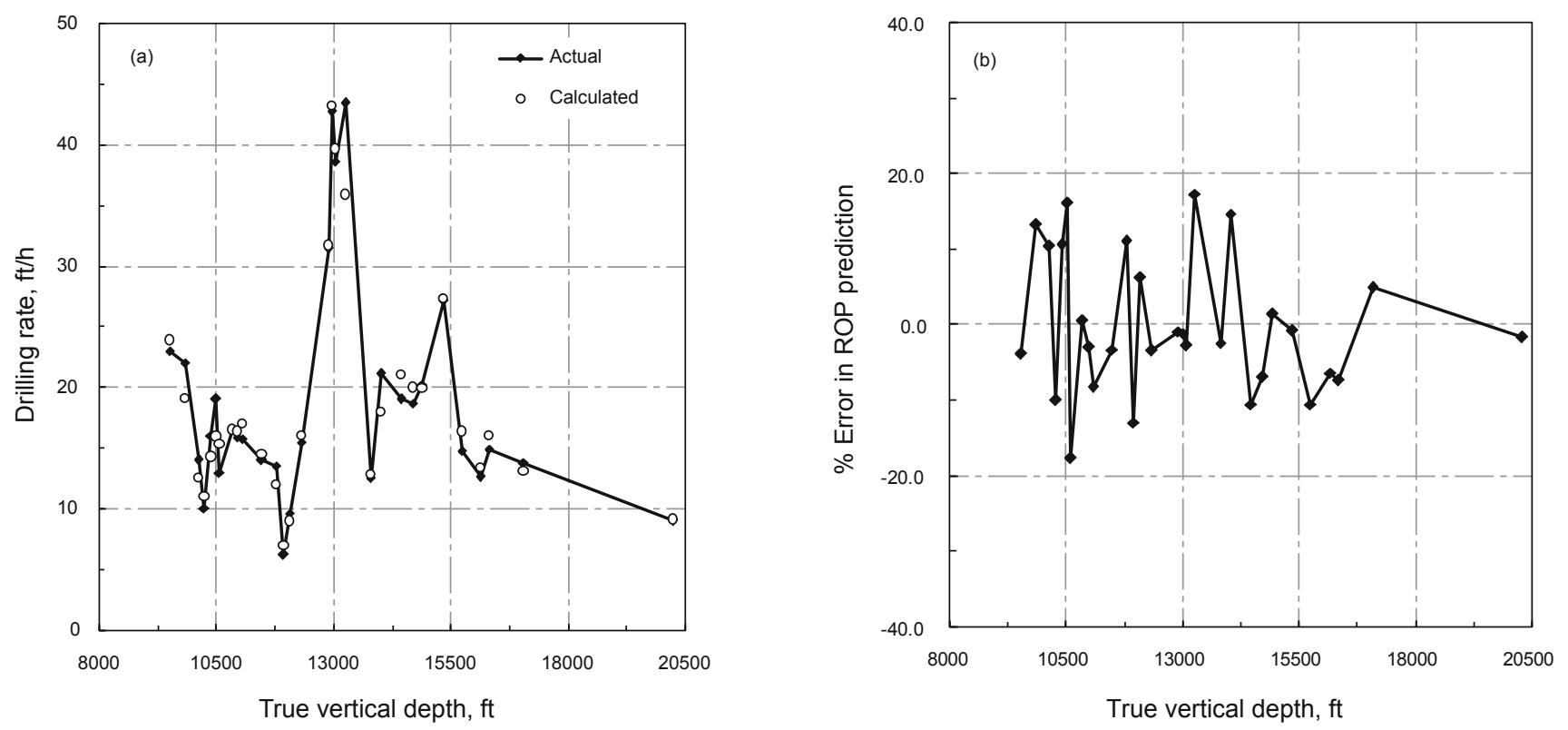

Fig. 2 (a) Comparison of actual rate of penetration with true vertical depth, and (b) percent error of prediction for rate of penetration with true vertical depth 


\subsection{Evaluation of the drilling model}

In general, the state variable equation for drilling operation is written in the form of ordinary differential equations (ODEs) and is given by Eq. (16).

$$
\frac{\mathrm{d} \boldsymbol{x}}{\mathrm{d} t}=f(\boldsymbol{x}, \boldsymbol{u}) ; \boldsymbol{x}(t=0)=\boldsymbol{x}_{0}
$$

where $\boldsymbol{x}$ and $\boldsymbol{u}$ are the state variable vectors and decision variable vectors respectively, and are are given by $\boldsymbol{x}=[D, h]^{\mathrm{T}}$ and $\boldsymbol{u}(t)=\left[N(t), W(t), \rho_{\mathrm{c}}(t), \operatorname{Re}_{\mathrm{f}}(t)\right]^{\mathrm{T}}$.

Eq. (16) is an initial value problem (IVP) and is integrated using the D02EJF subroutine (available in the NAG FORTRAN library) for any given $\boldsymbol{u}(t)$ and initial values of the state variables. This subroutine uses Gear's method (Gupta, 2010) to integrate a set of stiff ODEs. In this code, there is a provision for the adjustment of error tolerance. To calculate the error function in pore pressure equation (i.e., Eq. (14)), the S15AEF subroutine (available in the NAG FORTRAN library) is combined with the D02EJF subroutine. Drilling simulation is carried out for a given drill bit number with different combinations of $N, W, \rho_{\mathrm{c}}$ and $\mathrm{Re}_{\mathrm{f}}$ using Eq. (16).
In this study, the rock bit with bit class (1-3 to 1-4) has been considered and $\tau_{\mathrm{H}}$ (life of tooth at standard conditions) has been calculated using Eq. (3) for (i) $h=1$ (i.e., complete wearing of the drill bit), (ii) drilling time $\left(t_{\mathrm{b}}\right)$ and (iii) drill bit tooth wear parameters [i.e., $H_{1}, H_{2}, H_{3}$ and $(W / d)_{\max }$ ] for the offshore Louisiana formation (Bourgoyne and Young, 1974). Details of drilling time, drill bit tooth wear parameters and operating parameters (i.e., $N, W, \rho_{\mathrm{c}}$ and $\mathrm{Re}_{\mathrm{f}}$ ) used for drilling simulation are given in Table 2. Bit numbers 9, 18 and 21 (Table 2) are chosen for drilling simulation and results for drilling depth and drill bit fractional tooth wear with drilling time are shown in Figs. 3(a) and 3(b) respectively. This simulation procedure is quite general, and can be made for other drill bits. The simulation results (i.e., predicted drilling depth and fractional wear with drilling time) for drill bit No. 9, 18 and 21 are quite satisfactory and very much closer to the actual ROP (Bourgoyne and Young, 1974). Therefore, Eqs. (1), (2) and (5) can be used for finding the optimal values of the drilling variables through multi-objective optimization.

\subsection{Multi-objective drilling optimization}

The elitist non-dominated sorting genetic algorithm,

Table 2 Details of drilling parameters for simulation (Bourgoyne and Young, 1974)

\begin{tabular}{|c|c|c|c|c|c|c|c|c|}
\hline \multirow[b]{2}{*}{$\begin{array}{l}\text { Drill bit } \\
\text { No.* }\end{array}$} & \multirow[b]{2}{*}{ Time $t$} & \multirow{2}{*}{$\begin{array}{l}\text { Initial conditions } \\
\text { Normalized drilling depth } \\
D_{\mathrm{n}}(D / 20265), \mathrm{ft} / \mathrm{ft}\end{array}$} & \multicolumn{4}{|c|}{ Operating parameters } & \multirow[b]{2}{*}{$\begin{array}{l}\text { Drilling time } \\
\qquad t_{\mathrm{b}}, \mathrm{h}\end{array}$} & \multirow[b]{2}{*}{$\begin{array}{l}\text { Drill bit teeth } \\
\text { life } \tau_{\mathrm{H}}, \mathrm{h}^{* *}\end{array}$} \\
\hline & & & $\begin{array}{c}\text { Rotary speed } \\
\quad N \text {, rpm }\end{array}$ & $\begin{array}{c}\text { WOB } \\
W, 1000 \mathrm{lb} / \text { in }\end{array}$ & $\begin{array}{c}\text { ECD } \\
\rho_{\mathrm{c}}, \mathrm{lb} / \mathrm{gal}\end{array}$ & $\begin{array}{l}\text { Reynolds number } \\
\text { function } \mathrm{Re}_{\mathrm{f}}\end{array}$ & & \\
\hline 7 & 0 & 0.47 & 113 & 305.80 & 9.50 & 0.96 & 413.70 & 305.80 \\
\hline 8 & 0 & 0.49 & 126 & 10.23 & 9.50 & 0.96 & 14.32 & 10.23 \\
\hline 9 & 0 & 0.50 & 129 & 15.23 & 9.60 & 0.83 & 21.43 & 15.23 \\
\hline 11 & 0 & 0.51 & 87 & 4.21 & 9.70 & 0.98 & 12.00 & 4.22 \\
\hline 12 & 0 & 0.51 & 78 & 2.53 & 9.70 & 0.98 & 8.75 & 2.54 \\
\hline 13 & 0 & 0.53 & 67 & 3.83 & 9.80 & 0.93 & 27.11 & 6.52 \\
\hline 15 & 0 & 0.57 & 77 & 9.29 & 10.30 & 0.89 & 45.36 & 14.22 \\
\hline 18 & 0 & 0.58 & 58 & 4.58 & 11.80 & 0.85 & 22.22 & 4.59 \\
\hline 21 & 0 & 0.59 & 67 & 7.10 & 10.30 & 0.98 & 26.61 & 7.10 \\
\hline 22 & 0 & 0.60 & 84 & 5.30 & 15.70 & 0.99 & 13.54 & 5.30 \\
\hline 23 & 0 & 0.64 & 85 & 8.53 & 16.70 & 1.15 & 26.43 & 12.11 \\
\hline 24 & 0 & 0.65 & 77 & 0.76 & 16.70 & 1.22 & 1.76 & 0.77 \\
\hline 25 & 0 & 0.68 & 81 & 14.79 & 16.80 & 0.27 & 65.60 & 22.26 \\
\hline 26 & 0 & 0.69 & 75 & 2.75 & 16.80 & 0.20 & 10.19 & 2.76 \\
\hline 28 & 0 & 0.71 & 64 & 5.28 & 16.90 & 0.75 & 23.42 & 5.28 \\
\hline 29 & 0 & 0.74 & 75 & 3.46 & 17.20 & 0.42 & 22.28 & 7.43 \\
\hline 30 & 0 & 0.76 & 85 & 6.62 & 17.00 & 1.29 & 16.42 & 6.63 \\
\hline 32 & 0 & 0.80 & 80 & 12.64 & 17.90 & 0.67 & 63.89 & 24.52 \\
\hline 34 & 0 & 0.84 & 65 & 18.19 & 17.60 & 0.75 & 65.58 & 22.40 \\
\hline
\end{tabular}

Notes: * For a given drill bit number, the tooth wear parameters i.e., $H_{1}=1.84, H_{2}=6, H_{3}=0.80$, and $(w / d)_{\max }=8.0$ are considered for calculation with bit class 1-3 to 1-4.

** Drill bit teeth life is calculated using Eq. (3). 

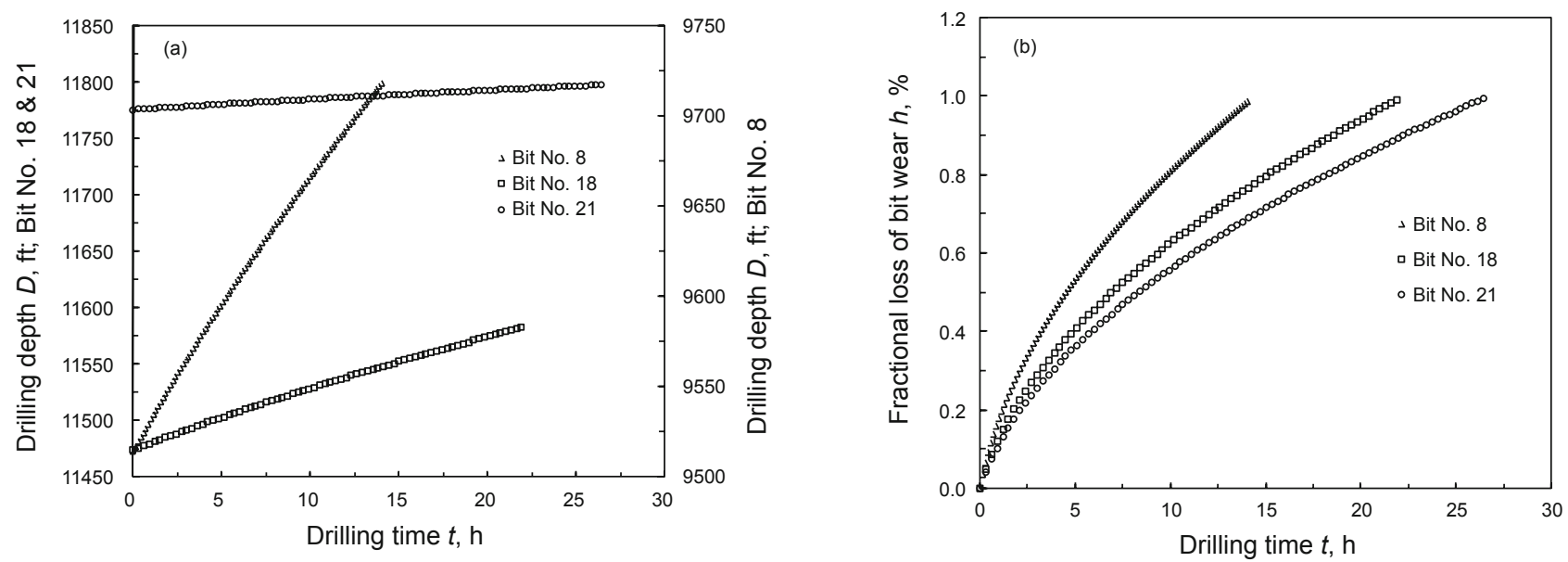

Fig. 3 Variation of (a) drilling depth and (b) fractional rate of drill bit wear with drilling time with different bits for a single bit run

NSGA-II, is used to solve multi-objective function optimization problems (i.e., Problems 2 and 3) involving time variant decision variables, namely, $N(t), W(t), \rho_{\mathrm{c}}(t)$ and $\operatorname{Re}_{\mathrm{f}}(t)$. The working principle of NSGA-II is based on the following tasks: (i) coding of the design or decision variables, (ii) evaluation of the objective functions and (iii) improvement of objective functions using genetic operators, namely, tournament selection, single point crossover, bit wise mutation and parent-daughter elitism. Details of NSGAII have been described by Deb and co-workers (Deb, 2001; Deb et al, 2002). An initial population of a given size is created using a random number generation subroutine. Using genetic operators (i.e., selection, cross over and mutation), the values of the objective functions will continue to improve by selecting better population of the decision variables. The subroutine D02EJF is combined with the adaptive version of NSGA-II optimization code for multi-objective optimization to solve initial value problem with multiple stiff differential equations. To account for continuous variation of the decision variables with drilling time for a single bit run, ten equally spaced points for each decision variable were generated randomly using a random number generator within its upper and lower limits for any drilling time interval. These equispaced decision variables are then fitted into a polynomial using the E02ACF subroutine (available in the NAG Library) to obtain time variant decision variables. Now interpolated polynomials [i.e., $\left.N(t), W(t), \rho_{\mathrm{c}}(t), \operatorname{Re}_{\mathrm{f}}(t)\right]$ are incorporated in the D02EJF subroutine for solving Eq. (16). To evaluate the values of error function in the pore pressure equation (Eq. (14)), the S15AEF subroutine (available in NAG Library) is also included with the D02EJF subroutine. Therefore, NSGAII code combined with three NAG subroutines (i.e., D02EJF: for solving IVP with multiple stiff ODEs; S15AEF: for evaluation of error function and E02ACF: for generation of time variant continuous decision variables) are used to solve the multi-objective optimization problems. The adaptive version of NSGA-II code is free of errors and tested using standards checks (Nayak and Gupta, 2004; Kachhap and Guria, 2005; Guria et al, 2005a; 2005b; Iqbal and Guria, 2009).

Eqs. (9) and (11) describe the multi-objective drilling optimization problems for the offshore Louisiana formation. First, Eq. (9) is solved that includes two-objective functions with four time variant continuous drilling variables, i.e., $N(t), W(t), \rho_{\mathrm{c}}(t), \operatorname{Re}_{\mathrm{f}}(t)$. In this problem, the normalized final drilling time $\left(t_{\mathrm{f}} / t_{\mathrm{ref}}\right)$ is minimized along with the maximization of final non-dimensional drilling depth $\left(D_{\mathrm{f}} / D_{\text {ref }}\right)$ for given limiting fraction of drill bit tooth wear. It is assumed that rig time (the sum total of rotating time, trip time during bit run and connection time) is also minimized when actual drilling time (i.e., drill bit rotating time) is minimized. The value of $t_{\text {ref }}$ and $D_{\text {ref }}$ are taken as $25.00 \mathrm{~h}$ and $20,265 \mathrm{ft}$ respectively. The studies are carried out for multi-objective optimization using drill bit No. 28 at a depth of $14,455 \mathrm{ft}$ (Table 2) to find the optimal values of the drilling variables for a single bit run. Details of the two-objective functions optimization problem are given in Column 2 of Table 3. Here bounds of the decision variables are based on exploratory drilling data of the Louisiana formation (Bourgoyne and Young, 1974). For example, ECD is chosen within the drilling mud window i.e., pore pressure gradient and fracture pressure gradient of the formation. At $14,455 \mathrm{ft}$ depth, the predicted fracture pressure gradient (Eq. (14)) and the pore pressure gradient (Eq. (5)) are calculated as $18.2 \mathrm{lb} / \mathrm{gal}$ and $16.4 \mathrm{lb} /$ gal respectively. Therefore, bounds of the ECD $\left(\rho_{\mathrm{c}}\right)$ are chosen as 16.4-18.2 $\mathrm{lb} /$ gal. Similarly, bounds of the other decision variables are chosen from Table 2. Eq. (9) is solved using NSGA-II and Fig. 4 shows the feasible optimal Pareto frontier for Problem 2 at the 100th generation. These solutions are clearly nondominated (non-commensurate) to each other. It is also found that the results at the 90th generation do not differ much from those at the 100th generation and one can reduce the computation time easily. The best values of the computational parameters used for this problem are given in Column 2 of Table 4 . The weighting factors $\left(w_{1}\right.$ and $\left.w_{2}\right)$ for this problem are fixed at $10^{7}$. A gap is observed in the optimal Pareto plots. Similar gaps have also been noticed by many researchers in computing intense multi-objective optimization problems (Kasat et al, 2002; Nayak and Gupta, 2004; Kachhap and Guria, 2005; Rangaiah, 2009, Guria, et al, 2009). In order to reduce this gap in Fig. 4, optimization was carried out for 200, 500 and 1,000 generations and there was no significant effect on the optimal Pareto solution with the increase in generation number. This is possibly due to the attainment of very close optimal values of all decision variables at the two extreme points in the gap, i.e., points ' $\mathrm{B}$ ' and ' $\mathrm{C}$ ' or ' $\mathrm{D}$ ' and 
'E' in Fig. 4 (Nayak and Gupta, 2004; Kachhap and Guria, 2005). Based on engineering judgment, a decision maker can select any preferred solution from the optimal Pareto frontier (Fig. 4). Here, we choose five different optimal solutions from Fig. 4 and marked as A, B, C, D and E with increasing drilling time for a single bit run. On minimizing only $f_{1}$, the shortest achievable time for drilling will obtain and this is shown by point $\mathrm{A}$ in Fig. 4. Similarly, maximizing only $f_{2}$, the final normalized drilling depth $\left(D_{\mathrm{n}}\right)$ is obtained which is the highest achievable drilling depth during drilling (i.e., point $\mathrm{E}$ in Fig. 4). Here, the points $\mathrm{A}$ and $\mathrm{E}$ are two limiting optimal solutions for the two-objective optimization problem. We also select points B, C and D (Fig. 4) randomly in between A and $\mathrm{E}$ on the optimal Pareto frontier and the decision maker may select any point on the basis of trade-off. The optimum values of the decision variables corresponding to these five different points (i.e., A, B, C, D and E in Fig. 4) are in shown in Figs. $5(\mathrm{a})-5(\mathrm{~d})$.

Table 3 Details of the multi-objective optimization problems

\begin{tabular}{|c|c|c|}
\hline Description & Problem 2 & Problem 3 \\
\hline \multicolumn{3}{|l|}{ Objective functions: ${ }^{*}$} \\
\hline First & Final drilling depth $\left(D_{\mathrm{f}} / D_{\mathrm{ref}}\right)$ & Final drilling depth $\left(D_{\mathrm{f}} / D_{\mathrm{ref}}\right)$ \\
\hline Second & Final drilling time $\left(t_{\mathrm{f}} / t_{\mathrm{ref}}\right)$ & Final drilling time $\left(t_{\mathrm{f}} / t_{\mathrm{ref}}\right)$ \\
\hline Third & - & Drilling cost $\left(C_{\mathrm{f}} / C_{\mathrm{ref}}\right)$ \\
\hline \multicolumn{3}{|l|}{ Constraint: } \\
\hline$h, \%$ & 0.75 & 0.75 \\
\hline \multicolumn{3}{|l|}{ Bounds of the decision variables: } \\
\hline$N, \mathrm{rpm}$ & $50-100$ & $50-100$ \\
\hline$W, 1000 \mathrm{lb} /$ in & $1.00-2.00$ & $1.00-2.00$ \\
\hline$\rho_{\mathrm{c}}, \mathrm{lb} / \mathrm{gal}$ & $16.45-18.20$ & $16.45-18.20$ \\
\hline $\operatorname{Re}_{\mathrm{f}}$ & $0.5-1.0$ & $0.5-1.0$ \\
\hline \multicolumn{3}{|l|}{ Model parameters: } \\
\hline \multicolumn{3}{|l|}{ Formation } \\
\hline Fracture pressure gradient $p p g_{\mathrm{fr}}, \mathrm{lb} / \mathrm{gal}$ & Eq. (13) (Fig. 1(a)) & Eq. (13) (Fig. 1(a)) \\
\hline Poisson's ratio $\mu$ & Eq. (14) (Fig. 1(b)) & Eq. (14) (Fig. 1(b)) \\
\hline Grain density $p p g_{g}, 1 \mathrm{~b} /$ gal & 24.88 & 24.88 \\
\hline Porosity decline constant $K, \mathrm{lb} / \mathrm{gal}$ & $8.4 \times 10^{-5}$ & $8.4 \times 10^{-5}$ \\
\hline Surface formation porosity $\phi_{0}$ & 0.3795 & 0.3795 \\
\hline \multicolumn{3}{|c|}{ Model constants for a depth range of 9500-20000 ft (Bourgoyne and Young, 1974) } \\
\hline$a_{1}, a_{2}, a_{3}, a_{4}, a_{5}, a_{6}, a_{7}, a_{8}$ & $\begin{array}{c}3.78,0.17 \times 10^{-3}, 0.20 \times 10^{-3}, 0.43 \times 10^{-4} \\
0.43,0.21,0.41 \text { and } 0.16\end{array}$ & $\begin{array}{c}3.78,0.17 \times 10^{-3}, 0.20 \times 10^{-3}, 0.43 \times 10^{-4} \\
0.43,0.21,0.41 \text { and } 0.16\end{array}$ \\
\hline \multicolumn{3}{|l|}{ Initial conditions for ODEs (Eqs. (1) and (2)) } \\
\hline Drilling time $t, \mathrm{~h}$ & 0.0 & 0.0 \\
\hline Fractional wear of drill bit, $\mathrm{h}$ & 0.0 & 0.0 \\
\hline \multicolumn{3}{|l|}{ Drill bit parameters } \\
\hline Bit number & 28 & 28 \\
\hline Bit class & $1-3$ to $1-4$ & $1-3$ to $1-4$ \\
\hline$(w / d)_{\max }, 1000 \mathrm{lb} / \mathrm{in}$ & 8.00 & 8.00 \\
\hline$(w / d)_{\mathrm{t}}, 1000 \mathrm{lb} / \mathrm{in}$ & 0.50 & 0.50 \\
\hline First constants for bit $H_{1}$ & Table 2 & Table 2 \\
\hline Second constants for bit $\mathrm{H}_{2}$ & Table 2 & Table 2 \\
\hline Third constants for bit $H_{3}$ & Table 2 & Table 2 \\
\hline Life of bit teeth at standard condition $\tau_{\mathrm{H}}, \mathrm{h}$ & 5.28 & 5.28 \\
\hline \multicolumn{3}{|l|}{ Rig parameters (Bourgoyne and Young, 1974) } \\
\hline Bit cost $C_{\mathrm{b}}, \$$ & - & 400 \\
\hline Rig cost $C_{\mathrm{r}}, \$ / \mathrm{h}$ & - & 500 \\
\hline Connection time $t_{\mathrm{c}}, \mathrm{h}$ & - & 1.00 \\
\hline Trip time $t_{\mathrm{t}}, \mathrm{h}$ & - & 6.00 \\
\hline
\end{tabular}

Notes: $* D_{\text {ref }}=20265 \mathrm{ft}, t_{\text {ref }}=25.0 \mathrm{~h}$ and $C_{\text {ref }}=20.0 \$ / \mathrm{ft}$ 


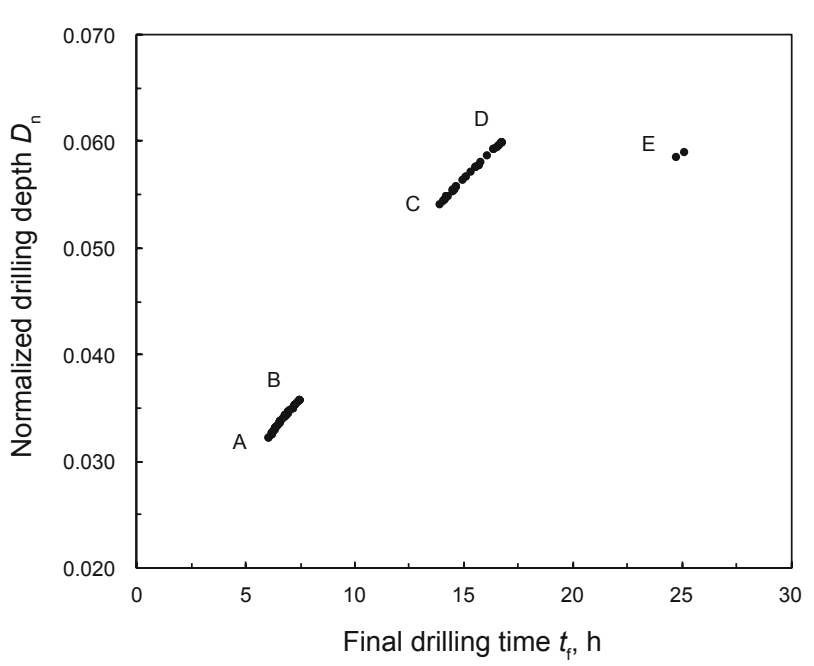

Fig. 4 Optimal Pareto solution for a two-objective optimization problem (Problem 2, Eq. (9))
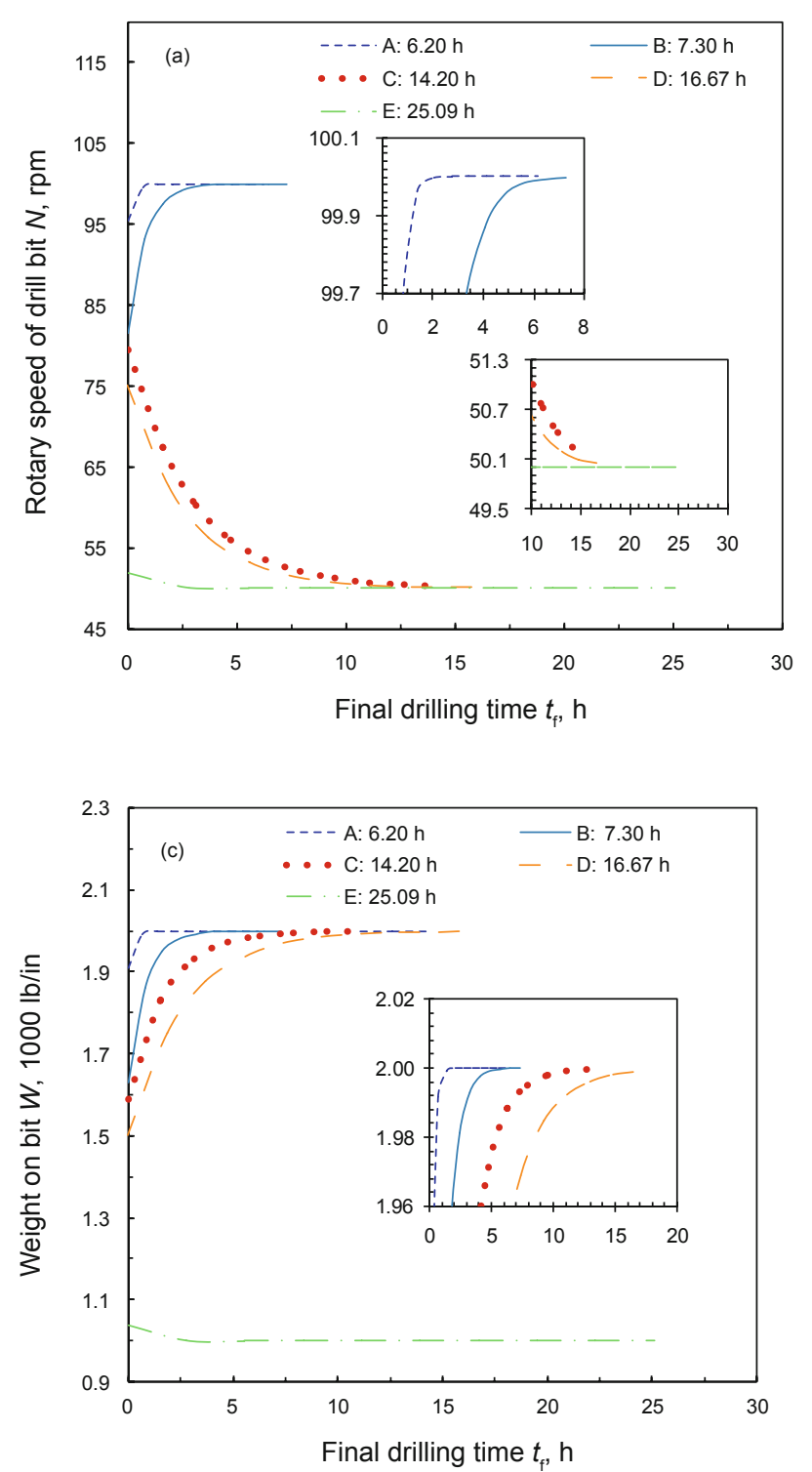

It is observed for the shortest final drilling time (i.e., point A in Fig. 4) that the optimum values of the decision variables (Figs. 5(a) $-5($ d): line A) remain almost at their highest limit. Similarly for the longest final drilling time (i.e., point E in Fig. 4), the optimum values of the decision variables particularly $N(t)$ and $W(t)$ remain almost at their lowest limit (Figs. 5(a) and 5(c): line E) whereas $\rho_{\mathrm{c}}(t)$ starts from the lowest possible value at the beginning of drilling and increases gradually with time after attaining an intermediate value at the end (Fig. 5(b): line E). $\operatorname{Re}_{\mathrm{f}}(t)$ also starts increasing from the lowest possible limit and attains the maximum possible limit at the end (Fig. 5(d): line E). For the intermediate values of final drilling time (i.e., Point B, C and D in the optimal Pareto front: Fig. 4), the optimum values of the decision variables are also varying with time (Fig 5(a)-5(d)). For these three points, it is interesting to note that the optimal values of $\rho_{\mathrm{c}}(t), W(t)$ and $\operatorname{Re}_{\mathrm{f}}(t)$ start from the intermediate values at the beginning of drilling and gradually
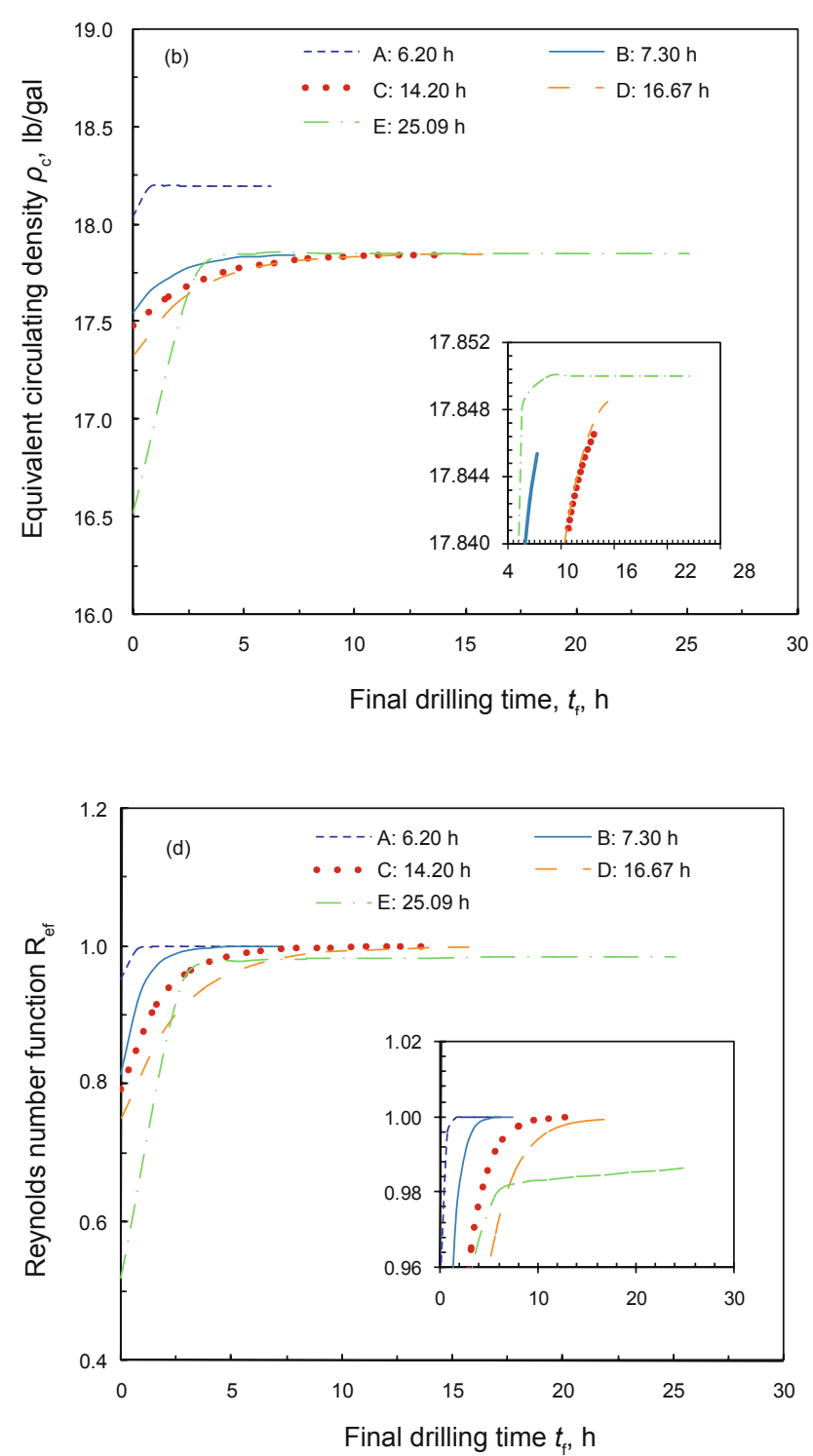

Fig. 5 Optimal variation of the decision variables i.e., (a) $N(t)$, (b) $\rho_{\mathrm{c}}(t)$, (c) $W(t)$ and (d) $\operatorname{Re}_{\mathrm{f}}(t)$ with drilling time for Problem 2 
increase with drilling time. Finally, they also attain a steady value at the end which is shown in Figs 5(b)-5(d) (lines: B, C and D). It is also noticed that the optimum values of $W(t)$ and $\operatorname{Re}_{\mathrm{f}}(t)$ are very close to the upper limit of the corresponding decision variables at the end of drilling (Figs. 5(c) and 5(d)), whereas $\rho_{\mathrm{c}}(t)$ remains at the higher intermediate value at the end (Fig. 5(b)) which is an indication of wellbore stability while drilling. The scenario is different for the optimal values of $N(t)$ while the optimal drilling. For the reduced final drilling time (Fig. 4: point B), the optimum values of $N(t)$ takes an intermediate optimum value at the beginning of drilling and gradually increases with time, attaining a steady value at the end which is also quite close to the upper limit of the decision variables (Fig. 5(a): line B). With an increase in final drilling time (Fig. 4: points $C$ and D), the optimum values of $N(t)$ start from the intermediate points and continue to decrease with time, attaining a steady value at the end which is very much closer to the lowest limit of the decision variables (Fig. 5(a): lines $\mathrm{C}$ and D). It is noted that the highest possible value of $\rho_{\mathrm{c}}(t)$ will be preferred for faster drilling to reduce the drilling time (Fig. 4 and Fig. 5(e): point E) whereas the intermediate values $\rho_{\mathrm{c}}(t)$ will be preferred for the moderate rate of drilling (Fig. 4 and Fig. 5(b): except point E). Therefore, the mutual adjustment of all the decision variables will help to improve ROP and will maintain well bore stability which are very much applicable to the real-life drilling operations.

Now, a three-objective functions optimization problem is solved involving time variant continuous drilling variables, i.e., $N(t), W(t), \rho_{\mathrm{c}}(t)$ and $\operatorname{Re}_{\mathrm{f}}(t)$ for given limiting fractional tooth wear of the drill bit. This problem deals with minimization of the normalized drilling cost $\left(C_{\mathrm{f}} / C_{\mathrm{ref}}\right)$, the maximization of final normalized drill depth $\left(D_{\mathrm{n}}\right)$ and the minimization of final normalized drilling time $\left(t_{\mathrm{f}} / t_{\mathrm{ref}}\right)$. The values of $C_{\text {ref }}$ is taken as $20.0 \$ / \mathrm{ft}$ in the present study. Details of this three-objective optimization problem are given in Column 3 of Table 3 and the best values of the computational parameters are given in Column 3 of Table 4. The weighting factors $\left(w_{1}, w_{2}\right.$ and $\left.w_{3}\right)$ for this problem are also fixed at $10^{7}$ for this problem. It is also mentioned that though the actual cost components of drilling operation may differ from the chosen values (Column 3 of Table 3), the optimization procedure is quite general and applicable for any values of cost data. Eq. (12) is solved using NSGA-II and Fig. 6 shows the feasible optimal Pareto surface for Problem 3 at the 100th generation. It is mentioned that all the points on the optimal Pareto surface are non-dominated (non-commensurate) to each other, and the decision maker can choose any point from this surface depending upon the trade-off involved during drilling. It is also found that the results at the 90th generation do not differ much from those at the 100th generation and one can reduce the computation time easily. Similar to Problem 2, any three points are selected randomly from the Pareto optimal surface with increasing order of drilling cost and marked as A, B and C (Fig. 6). The details of A, B and $\mathrm{C}$ points are also shown in Fig. 6. Variation of the optimal values of the decision variables [i.e., $N(t), W(t), \rho_{\mathrm{c}}(t)$ and $\operatorname{Re}_{\mathrm{f}}(t)$ are shown in Figs. 7(a)-7(d). The optimum values $N(t)$ starts with a higher value and gradually decreases with drilling time, attaining a steady values at the end, which is the lower limit of the decision variables (Fig. 7(a)). The initial high value of $N(t)$ will help to increase ROP and higher values of $N(t)$ is the preferred option to reduce the drilling cost. It is also observed that the optimum values of $\rho_{\mathrm{c}}(t)$ gradually increase with final drilling time and attain steady values at the end with a higher intermediate value. The optimal values of $\operatorname{Re}_{\mathrm{f}}(t)$ also increases with drilling time and attains a steady value at the end which is almost at the upper limit of the decision variable. The scenario is different for $W(t)$ as compared to $N(t), \rho_{\mathrm{c}}(t)$ and $\operatorname{Re}_{\mathrm{f}}(t)$. In order to reduce the cost of drilling operation (points $\mathrm{B}$ and $\mathrm{C}$ in Fig. 6), the optimum values of the decision variable takes always higher values at the beginning and attains a steady value at the end which is at the upper limit of the decision variables (Fig. 7(c): lines B and $\mathrm{C}$ ). For higher drilling cost (13.68 \$/ft: Fig 6, point A),

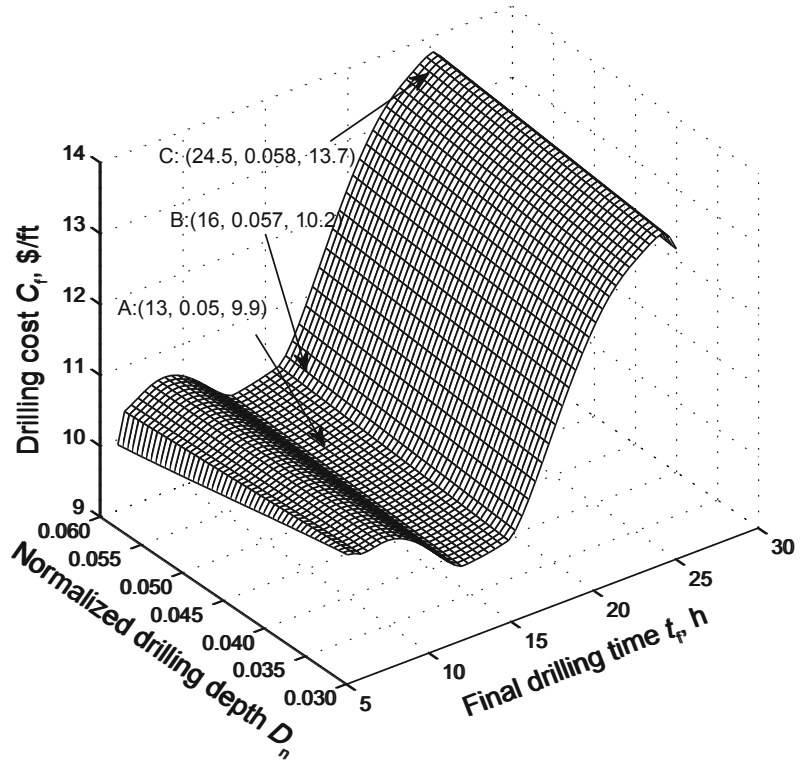

Fig. 6 Pareto optimal solution for three-objective optimization problem (Problem 3, Eq. (12))

Table 4 Computational parameters used for multi-objective optimization problems

\begin{tabular}{|c|c|c|}
\hline Description & Problem 2 & Problem 3 \\
\hline Number of objective functions & 2 & 3 \\
\hline Number of decision variables & 4 & 4 \\
\hline Number of constraints & 1 & 1 \\
\hline $\begin{array}{l}\text { Number of interpolating data points for } \\
\text { a decision variable }\end{array}$ & 10 & 10 \\
\hline Length of substring $l_{\text {substr }}$ & 32 & 32 \\
\hline Length of chromosome $l_{\text {chrom }}$ & $32 \times 40=1280$ & $32 \times 40=1280$ \\
\hline Maximum number of generations $N_{\text {gmax }}$ & 100 & 100 \\
\hline $\begin{array}{l}\text { Number of chromosomes in the } \\
\text { population } N_{\mathrm{p}}\end{array}$ & 100 & 100 \\
\hline Crossover probability $p_{\mathrm{c}}$ & 0.90 & 0.90 \\
\hline Mutation probability $p_{\mathrm{m}}$ & 0.01 & 0.10 \\
\hline Random seed number & 0.5789 & 0.5786 \\
\hline Computational time, $\min$ & 9.50 & 9.85 \\
\hline
\end{tabular}



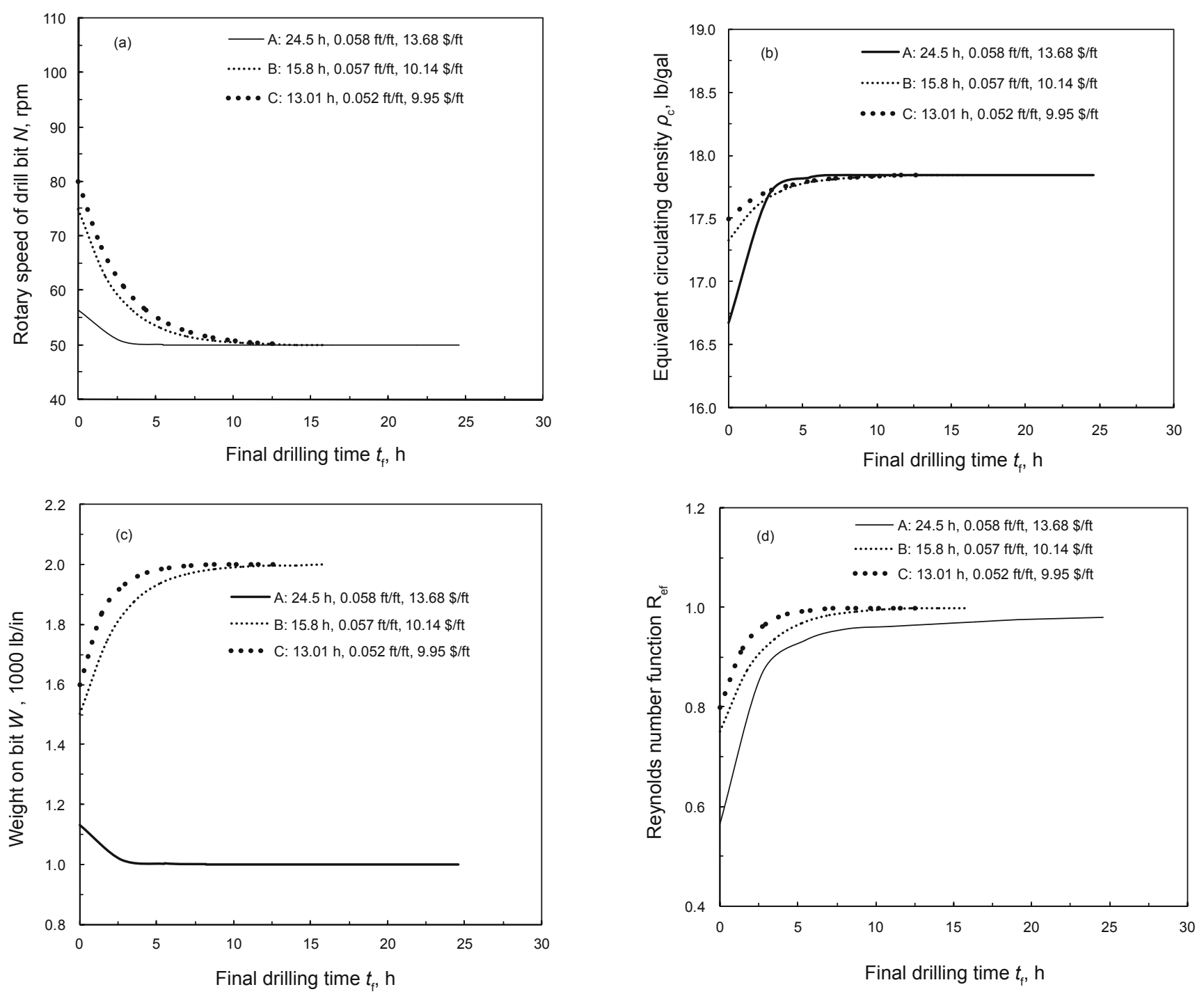

Fig. 7 Optimal variation of the decision variables i.e., (a) $N(t)$, (b) $\rho_{\mathrm{c}}(t),(c) W(t)$ and (d) $\operatorname{Re}_{\mathrm{f}}(t)$ with drilling time for Problem 3

the optimum values of $W(t)$ starts with a intermediate value at the beginning and attains a lowest possible steady value at the end (Fig. 7(c), line A). The initial higher values of the $W(t)$ is mainly to improve rate of penetration by reducing drilling time. It is mentioned that almost similar variation of these decision variables are also commonly noticed in real life drilling operation. The above multi-objective optimization procedure is quite general and can be applied easily for efficient drilling operation of developmental oil wells.

\section{Conclusions}

Multi-objective drilling operation of the Louisiana offshore field is carried out using binary coded elitist nondominated sorting genetic algorithm. Bourgoyne and Young's model is used to predict drilling depth and fractional drill bit tooth wear with drilling time. For the model based optimization, the variation of pore pressure gradient with true vertical depth is estimated by minimizing the weighted square of the errors between actual and predicted pore pressure. Several two- and three-objective optimization problems involving operating and economic criteria have been formulated and solved. The important objectives functions are: (i) maximization of the drilling depth, (ii) minimization of the drilling time, and (iii) minimization of the cost of drilling. The time variant decision variables present in the multi-objective optimization problems are: equivalent circulation density, rotary speed of the drill bit, weight on drill bit and Reynolds number function based on the circulating fluid through the drill bit nozzles. A set of equally good non-dominated optimal Pareto optimal frontier is obtained for the two-objective optimization problem. Similarly, a set of equally good non-dominated optimal Pareto surfaces is obtained for the three-objective optimization problem. Depending on the trade-offs involved among the objectives, the decision maker may select any point from the optimal Pareto frontier or optimal Pareto surface and corresponding time variant decision variables for the optimal operation of developmental oil well drilling. The optimum values of time variant decision variables are needed to be kept at the higher values to minimize drilling time and the drilling cost whereas drilling depth will be maximized by keeping the optimum values decision variables at the lower values. 


\section{Nomenclatures}

$a_{1} \quad$ Formation strength parameter

$a_{2} \quad$ Exponent of the normal compaction trend

$a_{3} \quad$ Under compaction exponent

$a_{4} \quad$ Pressure differential exponent

$a_{5} \quad$ Bit weight exponent

$a_{6} \quad$ Rotary speed exponent

$a_{7} \quad$ Tooth wear exponent

$a_{8} \quad$ Hydraulic exponent

$b \quad$ Bearing exponent in Eq. (4)

$B \quad$ Fractional bearing wear

$C_{\mathrm{b}} \quad$ Cost of bit, $\$$

$C_{\mathrm{f}} \quad$ Drilling cost per foot, $\$ / \mathrm{ft}$

$C_{\mathrm{r}} \quad$ Fixed operating cost of the rig per unit time, $\$ / \mathrm{h}$

$d \quad$ Drill bit diameter, in

$d_{\mathrm{n}} \quad$ Bit nozzle diameter, in

$D \quad$ Drilling depth, $\mathrm{ft}$

E Error in Eq. (6a)

$f_{1-3} \quad$ Objective functions

$F \quad$ Fitness function, Eq. (13)

$h \quad$ Fractional tooth height worn away

$H_{1}, H_{2}, H_{3} \quad$ Constants in Eqs. (2) and (3)

$K \quad$ Porosity decline constant, $\mathrm{ft}^{-1}$

$l_{\text {chrom } \quad \text { Length of chromosome }}$

$l_{\text {substr }} \quad$ Length of substring

$N \quad$ Rotary speed of drill bit, rpm

$N_{\mathrm{P}} \quad$ Number of chromosomes in the populatio

$N_{\mathrm{g}} \quad$ Generation number

$N_{\text {gmax }} \quad$ Maximum number of generations

$p_{p} g_{\mathrm{fr}} \quad$ Fracture pressure gradient, $\mathrm{lb} / \mathrm{gal}$

$p_{p} g_{\mathrm{g}} \quad$ Grain density, lb/gal

$p_{p} g_{\mathrm{p}} \quad$ Pore pressure of the formation, $\mathrm{lb} / \mathrm{gal}$

$p_{\mathrm{c}} \quad$ Crossover probability

$p_{\mathrm{m}} \quad$ Mutation probability

$\mathrm{Re}_{\mathrm{f}} \quad$ Reynolds number function based on nozzle diameter of drill bit

$t \quad$ Time, $\mathrm{h}$

$t_{\mathrm{t}} \quad$ Trip time during a bit run, $\mathrm{h}$

$t_{\mathrm{c}} \quad$ Connection time or non-rotating time, $\mathrm{h}$

$t_{\mathrm{b}} \quad$ Rotating time during a bit run, $\mathrm{h}$

$\boldsymbol{u}$ Decision variable vectors, Eq. (16)

$\frac{w}{d}=W(t) \quad$ Weight on bit per inch of bit diameter, $1000 \mathrm{1b} / \mathrm{in}$

$\begin{array}{ll}d & \text { Weighting factors }\end{array}$

\section{Greek letters}

$\mu \quad$ Poisson's ratio of formation

$v \quad$ Apparent viscosity at $10,000 \mathrm{~s}^{-1}, \mathrm{cP}$

$\phi \quad$ Average porosity

$\phi_{0} \quad$ Surface porosity

$\rho_{\mathrm{c}} \quad$ Density of the circulating drilling fluid, lb/gal

$\tau_{\mathrm{b}} \quad$ Formation abrasiveness constant or life of bearing at standard conditions, $\mathrm{h}$

$\tau_{\mathrm{H}} \quad$ Formation abrasiveness constant or life of tooth

Subscripts/Superscripts at standard conditions, $\mathrm{h}$

cal Calculated

d Desired f

g

L Lower bound of the decision variables

$\max \quad$ Maximum

$\min \quad$ Minimum

n Normalized

$\mathrm{p} \quad$ Pore

ref Reference

t Threshold

$\mathrm{U} \quad$ Upper bounds of the decision variables

$0 \quad$ Onitial condition/surface

\section{References}

Adams N J. Drilling Engineering: A Complete Well Planning Approach. Tulsa, Oklahoma: PennWell Publishing Company. 1985

Bahari A and Baradaran S A. Drilling cost optimization in Iranian Khangiran Gas Field. Paper SPE 108246 presented at the International Oil Conference and Exhibition in Mexico, 27-30 June 2007, Veracruz, Mexico

Bahari A and Baradaran S A. Drilling cost optimization in a hydrocarbon field by combination of comparative and mathematical methods. Petroleum Science. 2009. 6: 451-463

Bingham M G. A new approach to interpreting rock drillability. Oil and Gas Journal. 1964. 62: 80-85

Bourgoyne A T and Young F S. A multiple regression approach to optimal drilling and abnormal pressure detection. SPE Journal. 1974. 14: 371-384

Bourgoyne A T, Millheim K K, Chenevert M E, et al. Applied Drilling Engineering. Richardson, TX: SPE Textbook Series. 2003

Buckingham E. On physical similar systems; illustrations of the use of dimensional equations. Physical Review. 1914. 4: 345-376

Coello Coello C A, van Veldhuizen D A and Lamont G B. Evolutionary Algorithms for Solving Multi-objective Problems. New York: Kluwer. 2002

Deb K. Multi-objective Optimization using Evolutionary Algorithms. Chichester: Wiley. 2001

Deb K, Pratap A, Agarwal S, et al. A fast and elitist multiobjective genetic algorithm: NSGA-II. IEEE Transactions. Evolutionary Computation. 2002. 6: 182-197

Goldberg D E. Genetic Algorithm in Search, Optimization \& Machine Learning. New Delhi: Pearson Education Asia. 2001

Graham J W and Muench N L. Analytical determination of optimum bit weight and rotary speed combinations. Paper SPE 1349-G presented at SPE-AIME 34th Annual Fall Meeting, 4-7 October 1959, Dallas, Texas, USA

Guria C, Bhattacharya P K and Gupta S K. Multi-objective optimization of reverse osmosis desalination units using different adaptations of the non-dominated sorting genetic algorithm (NSGA). Computers \& Chemical Engineering. 2005a. 29: 1977-1995

Guria C, Verma M, Mehrotra S P. et al. Multi-objective optimal synthesis and design of froth flotation circuits for mineral processing using the jumping gene adaptation of genetic algorithm. Industrial \& Engineering Chemistry Research. 2005b. 44: 2621-2633

Guria C, Verma M, Gupta S K. et al. Optimal synthesis of an industrial fluorspar beneficiation plant using a jumping gene adaptation of genetic algorithm. Mineral and Metallurgical Processing. 2009. 26: 187-202

Gupta S K. Numerical Methods for Engineers (2nd ed.). New Delhi: New Age International Publishers. 2010

Han Y, Park C and Kang J M. Prediction of nonlinear production performance in water flooding project using a multi-objective evolutionary algorithm. Energy, Exploration \& Exploitation. 2011. 
29: $129-142$

Iqbal F. Drilling optimization technique-using real time parameters. Paper SPE 114543-RU presented at Russian Oil and Gas Technical Conference and Exhibition, Moscow, Russia. 2008

Iqbal J and Guria C. Optimization of an operating domestic wastewater treatment plant using elitist non-dominated sorting genetic algorithm. Chemical Engineering Research and Design. 2009. 87: 1481-1496

Jordan J R and Shirley O J. Application of drilling performance data to over pressure detection. Journal of Petroleum Technology. 1966. 18: 1387-1394

Kachhap R and Guria C. Multi-objective optimization of batch copoly (ethylene-polyoxyethylene terephthalate) reactor using different adaptations of non-dominated sorting genetic algorithm. Macromolecular Theory and Simulations. 2005. 14: 358-373

Kasat R, Kunzru D, Saraf D N, et al. Multi-objective optimization of Industrial FCC units using elitist non-dominated sorting genetic algorithm. Industrial \& Engineering Chemistry Research. 2002. 41: 4765-4776

Maidla E E and Ohara S. Field verification of drilling models and computerized selection of drill bit, WOB, and drill string rotation. SPE Drilling Engineering. 1991. 6: 189-195

Masseron J. Petroleum Economics (4th ed.). Paris: Editions Technip. 1990

Mitchell B J. Advanced Oil Well Drilling Engineering Handbook and Computer Programs (9th ed.). Dallas, TX: SPE Textbook Series. 1992
Nayak A and Gupta S K. Multi-objective optimization of semi-batch copolymerization reactors using adaptations of genetic algorithm (GA). Macromol Theory Simulation. 2004. 13: 73-85

Rangaiah G P. Multi-objective Optimization: Techniques and Applications in Chemical Engineering. Singapore: World Scientific. 2009

Rashid K. Optimal allocation procedure for gas-lift optimization. Industrial \& Engineering Chemistry Research. 2010. 49: 2286-2294

Ray T and Sarker R. Genetic algorithm for solving a gas lift optimization problem. Journal of Petroleum Science and Engineering. 2007. 59: 84-96

Rehm B and McClendon R. Measurement of formation pressure from drilling data. Paper SPE 3601 presented at the AMIE Annual Fall Meeting, 3-6 October 1971, New Orleans, USA

Reza M R and Alcocer C F. A unique computer simulation model well drilling: part I - the Reza drilling model. Paper SPE 15108 presented at the SPE 56th California Regional Meeting of SPE, 2-4 April 1986, Oakland, CA, USA

Singh H K, Ray T and Sarker R. Optimum oil production planning using infeasibility driven evolutionary algorithm. Evolutionary Computation. 2013. 21: 65-82

Tiwary P and Guria C. Effect of metal oxide catalysts on degradation of waste polystyrene in hydrogen at elevated temperature and pressure in benzene solution. Journal of Polymers and the Environment. 2010. 18: 298-307.

(Edited by Sun Yanhua) 